\title{
$\underline{\mathrm{O} J \mathrm{ED}}$
}

Volume 5, Issue 1 (2020), pp. 167-173

International Journal of

Multidisciplinary Perspectives in Higher Education ISSN: 2474-2546 Print/ ISSN: 2474-2554 Online https://ojed.org/jimphe

\section{Challenges and Opportunities for Teaching Students with Disabilities During the COVID-19 Pandemic}

\author{
Clinton Smith
}

The University of Tennessee at Martin, United States

\begin{abstract}
According to the United Nations Educational, Scientific, and Cultural Organization (UNESCO, 2020), school closures caused by the COVID-19 pandemic have affected over 1.5 billion students and families. The COVID19 pandemic has presented multiple challenges for teaching students with disabilities in an online instructional environment, but there are also opportunities for collaboration, training, and communication for special educators to meet the needs of their students.
\end{abstract}

Keywords: accessibility, collaboration, special education, technology, training

School closures caused by the COVID-19 pandemic have forced school leaders to shift to providing traditional instruction in an online environment. While online learning is not a new concept in the field of education, the quick shift of moving traditional education to a virtual setting was a daunting task in a short amount of time. Transitioning to a virtual setting forced many educators to learn new technologies and skills and caused stress among teachers and students. In addition to moving to an online learning environment during the COVID-19 pandemic, special educators were faced with multiple challenges ranging from equity issues for students, providing instruction in a virtual environment, and providing special education services as determined in student individual education plans 
(IEPs). However, the bigger the challenge, the bigger the opportunity for special educators as they learn to virtually teach in a pandemic world.

\section{Methodology}

To explore the impact of the COVID-19 pandemic of teaching students with disabilities, due to restrictions on social distancing and travel, the remote focus group method was chosen for this study. The participants were recruited through reaching out to members from a special education caucus group from a professional education association, who serve in a variety of educational settings including special education teachers and related service providers (e.g., school psychologists, speech therapists, occupational therapists). A total of thirty-five participants (9 men, 26 women) shared in three remote focus groups. The demographic make-up of the participants was 26\% European American male, 58\% European American female, $11 \%$ African American female, and 5\% Latin American female.

The researcher served as moderator for the remote focus groups which allowed fluid discussions to flow organically on the topic and allowed opportunities for sharing personal experiences of special educators during the COVID-19 pandemic. Participants were asked to share their experiences and challenges of teaching with students with disabilities in a virtual instructional environment. The remote focus group method allowed participants to express their views, opinions, and experiences which provided the researcher an opportunity to gain valuable insights for the present study.

\section{Challenges in an Online Instructional Environment}

The COVID-19 pandemic has exposed equity issues and challenges faced by all students, but especially for students with disabilities (Kaden, 2020; Sullivan et al., 2020; Tindle et al., 2017). A lack of equity is exhibited by the disproportionate access to technology and internet access for students who live in rural or low-income communities (Fishbane \& Tomer, 2020). Anderson (2019) found that for families earning less than $\$ 30,000$ per year, only $56 \%$ have access to broadband. The National Telecommunications and Information Administration (NTIA) stated that $13.8 \%$ or slightly over 3.1 million households do not have access to broadband connections in their homes which causes challenges to students being able to appropriately engage in an online learning environment (Fishbane \& Tomer, 2020). Teachers reported that almost $86 \%$ of their students had difficulties with internet access while $64 \%$ of students did not have appropriate technology devices needed for an online learning environment (Hamilton et al., 2020). In the same study, $38 \%$ of teachers also reported having inadequate access to the internet or technology. In focus groups, led by the author, participants stated that they were frustrated and discouraged with the lack of student and 
parent engagement. They felt that a lack of access to technology and internet access contributed to a portion of this disengagement.

Educators have learned that providing instruction in a classroom setting and providing instruction in an online setting is not only different but challenging (Young \& Donovan, 2020). In an online instructional environment, one difficulty faced by special educators is the ability to adequately provide special education services for students with disabilities, especially those with multiple or more significant disabilities. Many students with disabilities struggle with an online learning schedule because they need a more structured learning environment and interactions with their peers and teachers. This challenge is increasingly more difficult for students with disabilities who need access to such services as speech, occupational, or physical therapies (Schaeffer, 2020). Providing accessibility for students who are deaf or have hearing impairments as well as those with visual impairments in an online instructional environment is another challenge facing educators (Tandy \& Meacham, 2009; Debevc et al., 2011; Chowdhuri, et al., 2012; Alsadoon \& Turkestani, 2020). Shahenn and Watulak (2019) stated, "Inaccessible technologies are as problematic for disabled people as inaccessible buildings" (p. 187). Examples of accessibility issues include a lack of sign language interpreters for the deaf and hard of hearing, a lack of screen readers for those who have visual impairments or learning disabilities and providing captioning for English Language Learners.

Educators who lack technology training and resources face many barriers when teaching students with disabilities in an online environment. Hamilton et al. (2020) reported that $42 \%$ of teachers reported difficulty in receiving adequate support and guidance for working with students with disabilities. In the author-led remote focus group, participants shared that they struggled with the following: learning new technology, learning management systems, and how to provide online instruction, especially to students with disabilities. As a result of these challenges, educators are concerned that students with disabilities may experience a lack of progress due to a lack of providing much needed special education services.

A lack of consistent guidance in state and local education agencies regarding compliance to special education procedures is another challenge facing special educators. As of 2017, 84\% of states had no established or unclear policies concerning IEPs in virtual settings (Tindle et al., 2017). Tindle et al. (2017) also reported that twenty-two states had varying policies regarding accessibility and guidance for special educators. Special educators also noted that attempting to develop and implement IEPs in an online environment was much more difficult than in a traditional school setting (Tindle et al., 2017). In the author-led remote focus group, participants noted the same struggles and described being frustrated with the lack of 
consistency and confused by the guidance from their districts and state educational agencies as it relates to providing special education services.

\section{Opportunities and Implications for Practice}

As states and local education agencies plan for online education for students with disabilities in a pandemic world, they must recognize there are multiple opportunities that lay before them. This provides multiple opportunities for special educators to meet the needs of their students. Local education agencies and teacher preparation programs should provide training on the importance of socio-emotional learning, relationship building, collegiality, parent collaboration, and internet tools and safety (Collaborative for Academic, Social, and Emotional Learning, 2020; Smith et al., 2016). These opportunities have the potential for special educators to best meet the needs of their students and help them achieve their outcomes for success.

One opportunity is in the area of equity for technology and internet access. Local education agencies should survey families to determine accessibility of technology and internet access (Young \& Donovan, 2020). From these survey results, local education agencies can determine whether to provide computers, hotspots, or other technology devices to students for online education. Reich et al. (2020) recommended that when considering curriculum materials in online learning, schools should also incorporate non-digital alternatives (e.g., public television, printed packets) in addition to digital platforms such as Google Classroom or Khan Academy. Training in providing instruction in a virtual or alternative environment (e.g. home) using curriculum-based instructional activities, should be provided to educators so that they can ensure that students are working towards goals and objectives to meet outcomes.

Educators should consider incorporating the principles of universal design for learning (UDL) to provide accessibility for all students in an online instructional environment, but especially for students with disabilities. UDL is equitable because of its accessibility to students, flexible in use because it accommodates a wide range of learners and simple to use (Burgstahler, 2009). UDL provides a framework to remove barriers from instruction instead of providing accommodations through the principles of multiple means of representation, action and expression, and engagement (Schreffler et al., 2019). For example, educators can incorporate multiple means of representation by providing instruction through online activities, incorporating radio, podcast, or television broadcasts of academic content (Bender, 2020). An example of incorporating multiple means of action and expression would be providing students with flexibility for when and how they complete their schoolwork (Cook \& Grant-Davis, 2020; Kaden, 2020).

A second opportunity is in the area of special education policies and procedures. Federal and state education agencies should provide more 
consistent guidance for providing special education services in a pandemic world in order to ensure that students with disabilities are provided with services and instruction (Reich et al., 2020). The Office of Special Education Programs (OSEP) provides guidance that school districts must provide access to educational opportunities, including a free and appropriate public education, and special education services to students with disabilities if it provides educational opportunities for the general school population (OSEP, 2020). State and local education agencies should maintain consistent communication and clarity for expectations for providing special education services through guidance documents and websites (Young \& Donovan, 2020). Local education agencies should ensure that special educators have manageable caseloads so that they can effectively provide services. Educators should be concerned about compliance with special education laws and guidance, but also focus on outcomes for students with disabilities.

With challenges come opportunities. The pandemic crisis has provided educators with several challenges in providing learning in a virtual environment. There are more opportunities to expand their instructional repertoire by implementing various instructional methods by engaging students using virtual learning strategies and platforms, incorporating the principles of UDL, inviting collaboration with fellow educators, and maintaining communication with students and parents. School administrators and systems must seize the opportunity to ensure that educators are prepared for teaching in a pandemic world and focus their efforts to provide more technology resources and training as well as prepare clear and consistent guidance for delivering special education services for students with disabilities.

\section{References}

Alsadoon, E. \& Turkestani, M. (2020). Virtual classrooms for hearingimpaired students during the COVID-19 pandemic. Romanian Journal for Multidimensional Education, 12, 2-8.

Anderson, M. (2019). Mobile technology and home broadband 2019. Pew Research Center, 2.

Bender, L. (2020). Interim Guidance for COVID-19 Prevention and Control in Schools. UNICEF.

Burgstahler, S. (2009). Universal Design of Instruction (UDI): Definition, Principles, Guidelines, and Examples. DO-IT.

Chowdhuri, D., Parel, N., \& Maity, A. (2012, July). Virtual classroom for deaf people. In 2012 IEEE International Conference on Engineering Education: Innovative Practices and Future Trends (AICERA) (pp. 1-3). IEEE.

Collaborative for Academic, Social, and Emotional Learning. (2020). https://casel.org/ 
Cook, K.C. \& Grant-Davis, K. (2020). Online education: Global questions, local answers. Routledge.

Debevc, M., Kosec, P., \& Holzinger, A (2011). Improving multimodal web accessibility for deaf people: Sign language interpreter module. Multi-timed Tools Appl, 54(1), 181-199.

Fishbane L. \& Tomer A. (March, 20, 2020). As classes move online during COVID-19, what are disconnected students to do? https://www.brookings.edu/blog/the-avenue/2020/03/20/as-classesmove-online-during-covid-19-what-are-disconnected-students-todo/

Fry-Bowers, E. K. (2020). Children are at risk from COVID-19. Journal of Pediatric Nursing, 53, A10-A12.

Hamilton, L. S., Kaufman, J. H., \& Diliberti, M. (2020). Teaching and Leading Through a Pandemic: Key Findings from the American Educator Panels Spring 2020 COVID-19 Surveys.

Kaden, U. (2020). COVID-19 School closure-related changes to the professional life of a K-12 teacher. Education Sciences, 10(6), 165.

Office of Special Education Programs. (March 12, 2020). Questions and Answers on Providing Services During the Coronavirus Disease 2019 Outbreak. ahttps://sites.ed.gov/idea/files/qa-covid-19-03-122020.pdf

Reich, J., Buttimer, C. J., Fang, A., Hillaire, G., Hirsch, K., Larke, L. R., ... \& Slama, R. (2020). Remote learning guidance from state education agencies during the covid-19 pandemic: A first look.

Schaeffer K. (April 23, 2020). As schools shift to online learning amid pandemic, here's what we know about disabled students in the U.S. https://www.pewresearch.org/fact-tank/2020/04/23/as-schools-shiftto-online-learning-amid-pandemic-heres-what-we-know-aboutdisabled-students-in-the-u-s/

Schreffler, J., Vasquez III, E., Chini, J., \& James, W. (2019). Universal design for learning in postsecondary STEM education for students with disabilities: A systematic literature review. International Journal of STEM Education, 6(1), 8.

Shaheen, N. L., \& Lohnes Watulak, S. (2019). Bringing disability into the discussion: Examining technology accessibility as an equity concern in the field of instructional technology. Journal of Research on Technology in Education, 51(2), 187-201.

Smith, S. J., Basham, J. D., Rice, M., Carter, R. A., Jr. (2016). Preparing special education teachers for online learning: Findings from a survey of teacher educators. Journal of Special Education Technology, 31(3), 170-178.

Sullivan, F., Hillaire, G., Larke, L., \& Reich, J. (2020). Using teacher moments during the COVID-19 pivot. Journal of Technology and Teacher Education, 28(2), 303-313. 
Tandy, C., \& Meacham, M. (2009). Removing the barriers for students with disabilities: Accessible online and web-enhanced courses. Journal of Teaching in Social Work, 29(3), 313-328.

The United Nations Educational, Scientific, and Cultural Organization. (2020). Learning never stops - tell UNESCO how you are coping with COVID-19 school closures. https://en.unesco.org/news/learning-never-stops-tell-unesco-howyou-are-coping-covid-19-school-closures-0

Tindle, K., East, B., \& Mellard, D. (2017). Online learning for students with disabilities: Considerations for LEA policies, practices, and procedures. Center for Online Learning and Students with Disabilities. http://www.centerononlinelearning.res.ku.edu/wpcontent/uploads/2017/05/LEA_ResourceDoc_April2017.pdf

Toquero, C. M. D. (2020). Inclusion of People with Disabilities amid COVID-19: Laws, Interventions, Recommendations. Multidisciplinary Journal of Educational Research, 10(2), 158-177.

Young, J., \& Donovan, W. (2020). Shifting to Online Learning in the COVID-19 Spring. Policy Brief. Pioneer Institute for Public Policy Research.

\footnotetext{
Author Bio

Clinton Smith, Ed.D., BCBA-D, LBA, is an Associate Professor of Special Education at The University of Tennessee at Martin. His major research interests focus on special education, autism, behavioral consultation, multitiered systems of support, and classroom management. Email: csmit279@utm.edu
} 